TV-aktualitetsudsendelserne kan kun lose denne type af problemer, ved enten at sprenge den autoritative fremstillingsform, sadan som f.eks. Poul og Nulle og Damgaard og Carlsen er godt igang med - eller ogsa betjene sig af den mere sofistikerede balancegang mellem ironi og parafrase, som Elindt Petersen og stephensen ofte er mestre $i$.

\title{
I.TTTERATURHENVISNINGER
}

Chr. Alsted: Bag om Baggärden. i: Sekvens 1983.

Eigil Andersen m.fl.: Ikke et ord on ytringsfrihed. Arhus 1977.

Susan Boyd-Bownan: 'The Day After': Representations of the Nuclear Holocaust. Screen 1985.

John Carlsen: Det gode fJernsyn. Arhus 1984.

Mette Ewald: skriften på vaggen står mellem linjerne. Ungdomsredaktionen. 1: Ny ungdom - nye medier. Kbh. 1987.

J. Fiske og J. Hartley: Fjernsynets sprog. Kbh. 1981.

Wolfgang Isex: Dex implicitte Leser. München 1972.

Helle D. Jensen og C. Rosenbeck: Difus eller finnase. Projektrapport, AuC 1985.

Angela Keppler: Präsentation und Information. Die Massenmediale Konstruktion dex Wirklichkeit. i: Medium 8, 1985.

Peter Kofoed og Tove Rasmussen: Dallas - skabelon og struktur i den moderne TV-sexie. Aalborg 1985.

Kim Minke og M. Meilby: Når sandheden skal frem. Koh. 1983.

F. Mortensen, J. Poulsen, P. Sepstrup (red.): Underholdning i TV. KBh. 1981.

Ralf Pittelkow (red.): Analyser af TV. Kbh. 1985

Michael Schudson: The Politics of Narrative Form: The Energence of News Conventions in Print and Television. i: Daedalus 4, 1982.

Bernward Wember: Wie informiert das Fernsehen? Munchen 1983.

Jørgen Stigel er lektor ved Aalborg Universitetscenter, Institut for Kommunikation. 


\section{Tilbageblik på "Heimat"}

\section{Af Niels-Aage Nielsen}

"Heimat" hedder den vesttyske serie pa 11 afsrit, som inden for godt et ars tid er blevet vist i bade dansk og suensk tw. Serien er produceret for west-Deutsche Rundfunk og dens instruktor hedder EDGAR REITZ. Den blev genstand for debat pressen pä grund af dene historiske behanditing af nasi-tialen. $I$ den folgende artikel Lader Niels-Aage Nielsen denne debat ligge og spger $i$ stedet at belyse nogle af de trak ved serien, som gor, at den i sa hoj grad virker "fortalt i fortid". Hoorfor kan fitmens og tv's aktuelle og levende bitheder fungere som om der fandtes datidsformer i bitledsproget? En del af teorien $i$ artiklen stammer fra fremstizingen af Gizies Deleuse's filmastetik andetsted i dette numbr.

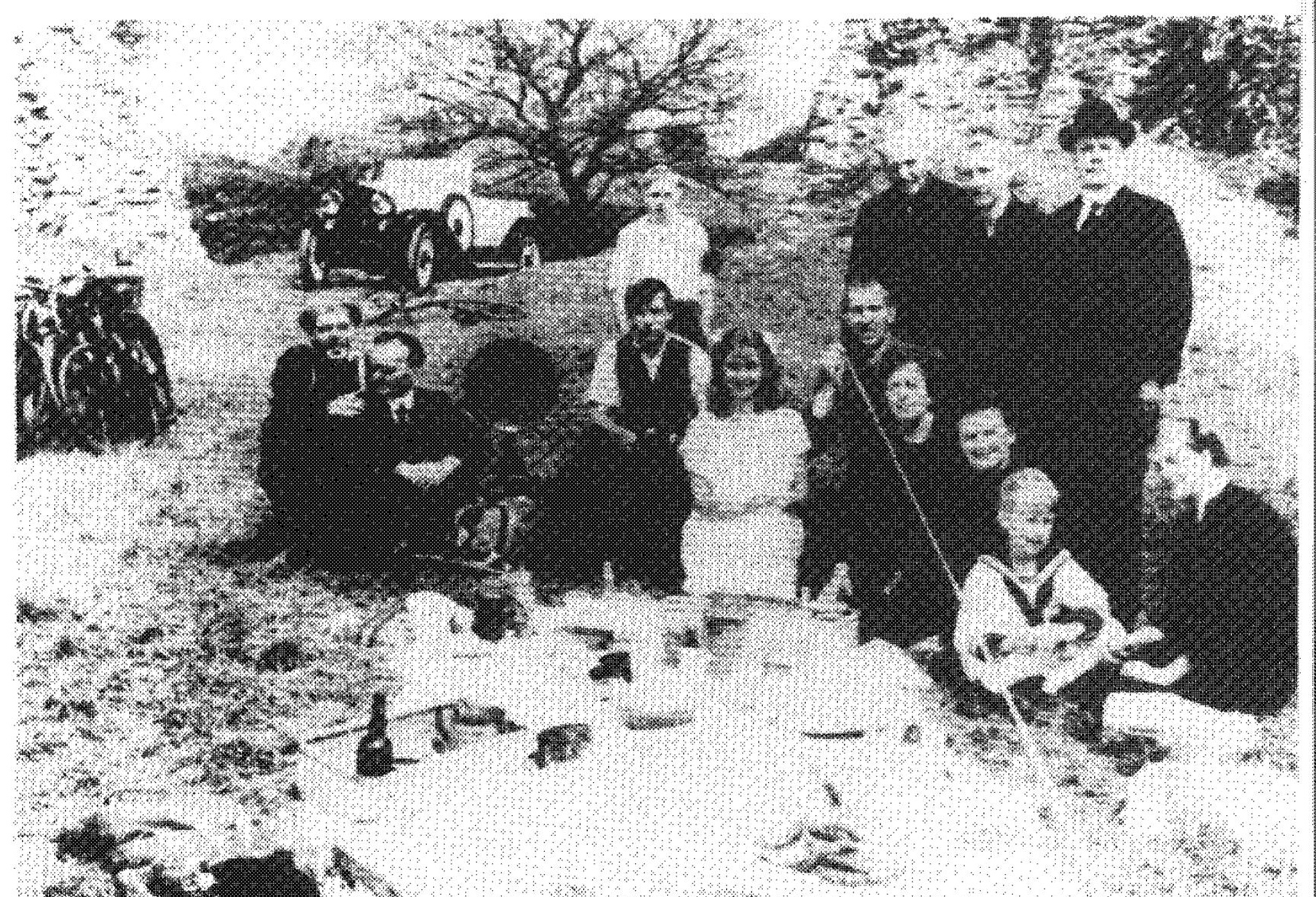


Denne artikel vil ikke vere en udtømmende analyse på kryds og tvars af den lange serie, men derimod bringe nogle overvejelser frem omkring de billeder, serien bygger pă. Kort sagt: hvad er det for nogle billeder Edgar Reitz viser os, og hvad skal de fortælle? I og for sig betragter jeg serien selv som et a propos til en ny teori om levende billeder, som jeg prasenterer andetsted $i$ dette numer. Hovedideen er, at der i "Heimat" findes en sarlig art billeder, som kan kaldes tidsbilleder. Denne slags billeder betinger en dramaturgi, som man måske kan driste sig til at kalde "dramatik 1 tiden".

\section{Synligt-usynligt}

Edgar Reitz har selv skrevet nogle meget interessante ting om Heimat, som det er vard at tage til efterretning. ") Han siger, at netop fordi kameraobjektivet synes sa fikseret på at registrere og gengive de synlige ting, sa har filmens tema egentlig altid veret at skildre det usynlige. Pa paradoksal made handler film on usynlige ting igennem kameraets maniske afbilaning af det synlige. Selve paradokset er, at filmens blikfangende billeder, trods blikfanget, fortaller usynlige historier. For historierne 1 film er usynlige. De foregar i forsvindingspunkter mellem billederne.

Dette paradoks har "action-filmen" ikke forståt. (Måske kan man generalisere endnu mere og sige at dette paradoks ikke er bevidst som stetisk princip i den amerikanske model for fortallende 11 im som gar tilbage til Griffiths "Birth of a Nation". Princippet i denne kvantitativt dominerende filmtype er groft sagt, at fortilingen bliver til igemnem de synige handinger, som personerne $i$ blilederne udforer 1 forhold til ting, miljф og hinanden. Betydninger fremkommer af vekselvirkningen mellem adfard og miljø og adfard versus adfard).

Som Reitz navner, sa anvendes der i action-1ilm kæmpesummer på at iscenesatte biljagter, slagsmal, katastrofebrande og andre stunts, men intet hjelper det, hvis vi ikke far fortalt smerten, angsten og lysten. Men disse ting ex komplet usynlige. 
Reitz formulerer sit paradoks derhen, at netop fordi vi i filmen $i$ den grad bindes til фjets indtryk, så forveksler vi ikke den egentlige historie med $\phi j e t s$ indtryk. At $\phi j e t$ på en măde beskeftiges ellex optages sadan, at den usynlige historie bliver frigjort.

Det er altsa ligeson med odysseus, der matte bindes til masten for likke at rore ved det sanselige. Reitz mener, at filmens paradoksale opfindelse ex at gore oplevelsen af det ikkesanselige sa meget starkere, som $\phi j e t$ bindes til larredet.

Tankegangen er interessant, fordi den drejer sig om det vanskelige problem at forsta, hvori de levende billeders fascinationskraft bestar.

Efter min mening er der det rigtige i tankegangen, at filmbilleder $i$ hфjeste grad kan skildre det usynlige. Derimod er det liat uklart at forst: hvordan en sadan skildring kan vare direkte funktion af $\varnothing j e t s$ binding til starke indtryksbilleder. Jeg tror derimod, at billeder kan være starke pa flere forskellige mảder, og at der findes en sarlig slags billeder som tjener skildringen af det usynlige. Det er de săkaldte tidsbilleder, og man finder dem i Reitz' egen serie.

De fleste vil vel ud fra deres sunde fornuft mene, at hvis en usynlig dimension kan fojes til det synlige, sa er det fordi forestillingsbilleder kan hentes frem fra bevidsthedens magasin og knyttes til perceptionen. Hvordan skulle det sa kunne gà til, at man kan tilfoje sa meget mere usynligt til den aktuelle perception jo sterkere ens blik er fanget. Man skulle tro det var omvendt. Jo svagere billede som f.eks. af en genstand i tusmorke, jo mere forestilingsarbejde skal der til for at opfatte.

Løsningen på problemet, hvor man samtidig bevarer tanken om en stark fascination $i$ billederne, ex, at der findes en sarlig art af starke billeder, som objektivt set er gennemsigtige og gennemtrangt af det usynilge - narmest som en tidslig dybde 1 dem. 
M. Merleau-Ponty kan give os ei ide om problemet: 2$)$

"denne $r$ doe farve er kun, hvad den er, ved fra sit sted at sta $i$ forbindelse med andre rode farver omkring den og ved sammen med dem at danne en vis konstellation, eller sammen med andre farver, som den dominerer, eller som dominerer den, som den tiltrakker eller som tiltrakker den, som den frastøder eller son frastoder den. Den ex kort sagt et bestemt knudepunkt $i$ det samtiaiges og forlobets fletvark. Den ex en konkretion af selve synligheden, den er ikke et atom. Desto mere galder det, at den rode kjole i hver trăd tilhprer det synliges struktur og hermed en struktur af usynlig varen. Den ex et enkelt tegn i feltet af rode ting, som omfatter tagenes teg1, ledvogternes flag og revolutionens fane, jordbunden ved Aix ellex pa Madagascar.... En bestent rod farve er ogsá et fossil, hentet dybt i imaginare universer".

Perception ex jo for Merleau-Ponty forst og fremest en sporgende eksistens, og formodentijg opnăr de forneunte billeder heller ikke deres usynlige dybde med mindre de på en eller anden måde inviterer til spørgsmal. Bllleder i hvilke betydningen stax til. debat med sig selv. Hvor genkendelsen midlertidigt blokeres: hvor har jeg set dette for?

\section{Passiviteten i "Heimat" .}

Efter min mening findes der ikke ret mange sekvenser i "Heimat" , hvor en betyaning frengar af en udfort handing. Derimod ofte hvor personex blokeres $i$ deres handinger eller "svaver" i situationer. Personerne "standses" 1 deres handinger og fikseres $i$ et hukommelsesperspektiv. Det galder f.eks. detaljer, som dex, hvor direktoren fra "unilever" ex pa vej gennem skoven i sin limousine for at kobe Antons optiske fabrik. Pluaselig standser. bilen pa grund af en kronhjort, og i et meget langt sekund fanger hjorten direktфrens blik, og gennemlyser ham pa det narmeste.

Eller der, hvor otto skal demontere sin sidste bombe. Midt i afskruningen af den uheldssvangre detonator, kommer en gammel mand medkasket og jernbanevarkt bombehullet. "Hvad laver du her," siger otto. "Jeg kontrollerer strækningen," svarer manden og tilf tidligere". log det ved vi godt, for manden optråde allerede 1 afsnittet lige efter forste verdenskrig). Han er stadig i tjeneste, eller rettere han ex altid i tjeneste. Egentlig ex han 
ikke døden, som kommer eftex otto, for han har $\phi j e n s y n l i g ~ i k k e$ set en bombe $f \not r, ~ o g$ han gar lydigt vak, da otto beordrer ham væk fra stedet. Hvis han ex noget, ex det blot den, der vil finde liget og tage sig af det, nar han pa sin inspektionsrunde komer forbi. Eorst og fremmest er han imidlertid en, der gennemlyser dybderne i otto's sidste time.

Og saddan forholdex faktisk alle personerne sig til hinanden og til de situationer, hvori de skildres. Det er, som om de krystalliserer hinanden, og deres livsфjeblikke.

Strengt taget er det smat med handinger i serien. Jo, de kommer, og de găr, og vender tilbage. Og de korer og flyver, og laver radio, fotograferer, komponerex musik, er Bürgermeister i nazitiden og gar 1 uniform, har en fabrik osv. Men det drejer sig aldrig rigtig om, hvad de far ud af det, hvad det forer til, og hvad de vil med det. Der er f.eks. to fabriksherrer 1 serien, nemlig Paul og hans son, Anton. Pauls primare formal med sin fabrik 1 USA synes at vare dec at kunne komme sejrrig hjen og bespise sine bysborn, samt lege med elektronik. Og Antons identi-tet ex de forgyldte, krystalliserede stфvler, som symboliserer den lange march, hvor han fik ideen til fabrikken.

Allerede den lange sekvens i forste afsnit, hvor Paul er kommet hjem, og hvor de alle sidder i køkkenet, og Eduard laser avis, og Paul ser syner, og den en-фjede Hänschen glor pă dem ind ad vinduet - fortaller os forst og fremmest, at der egentlig ikke sker en skid 1 disse billeder, men noget foregar.

Derfor kan det undre, at nogen for alvor har villet se disse mennesker som opdelt i modstandere og tilhangere, medlobere og oprørere, røde og sorte. Som om de var lidt adrligere end dem, der er 1 "Matador". Her er der jo ogsa langt mellem de handlingsauelige og sabotoreme. I "Heimat" er der endnu farre. Og det er ikke, fordi flimen foregar næmere ved forerbunkeren og koncentrationslejrene.

Der er den afgфrende forskel pa personerne $i$ de to serier, at dem i "Matador" til enhver tid kan sta frem og legitimere sig selv. 
De er skildret 1 al deres selvretfardige holden-sig-uden-for, ellex hule og pålistede idealisme. Medens dern "H "Hemat" er skildret $i$ en sa pinagtig passivitet, at man ikke kan undgå den tanke, at de måske er passive $i$ en helt anden forstand end $i$ rollen som modspillere til nazi'erne.

Personerne i "Heimat" tilhører nemig aødsriget. Og for at vi ikke skal misforsta det, har Reitz sat flere kors end hagekors 1 billederne. Ofte ses personeme igennem vinduer, hvis ramer Iigesom satter et kors over dem. F.eks. ses Wiegand, da han hygger sig juleaften $1934 \mathrm{med}$ den nazistiske juleplade, igennem et sadant korsvindue. Og da Paul på Ellis rsland far hjemve, fortsatter kameraet 1 en travelling ud af et sadant korsvindue hen over de gronne maxker i Schabbach, sadan at korset vel at marke ses som skygge i foxarskornet. Og Anton slăr et kors op pa fodehjemmet, for at ingen mere skal komme ud eller ind. Og vinduer og bindingsvark på huset danner kors. Og på kirkegarden, hvor Hermännchen vandrer rundt, er der masser af kors.

Foruden kors ex der sat sten. Der er sat sten i vignetten til hvert afsnit. Dex er sten pa kirkegarden, hvori pexsonerne ofte spejles. Og der ex sat sten over faldne soldater.

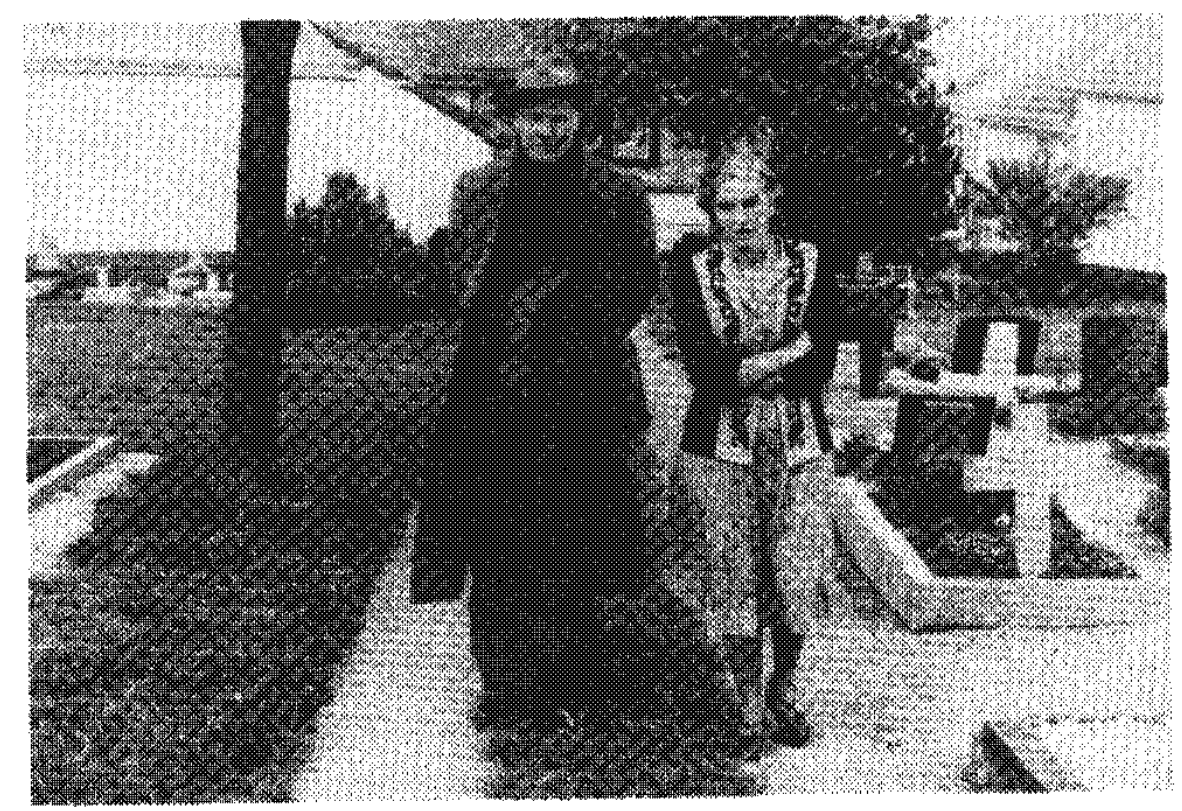

Pauı og Maria på kixkegărden. Hun sporger ham, hvorfor han egentilg forlod hende og bornene for omkring en generation siden. 
Det synes helt ydeligt, at dødens skygge hviler over disse mennesker. At det, der skildres, er passe, fini. Som Reitz udtrykker det, sa marker vi afskedens sorg 1 billederne. Ofte er personernes skygger stфrre end dem selv, hvilket som regel forst indtreffer hen under aften, nar sindet vandrer tilbage $i$ det skete.

\section{Fortidens modus}

Selvfolgelig lever vi altid i nu"et og ingen andre steder. Men nu'et kan trakke sig sammen til nasten ingenting alt efter, hvordan hukommelsens rum tranger sig ind på det.

Historier udspiller sig i fortiden, og horer til hukommelsen. Men de kan fortalles på forskellig måde, og derved andre karakteren af fortalingsdjeblikket. For det forste kan man angive den narmere datering og omstandighederne ved en fortalling, der udspiller sig $i$ fortiden, men derefter aktualisere den som on fortidens begivenheder genuaspillede sig her og nu. vores ojeblik overtages af fortidsiktionen, der egentig udspiller sig som en hvilken som helst фjebliksaktualitet. Trods det at historien foregar $i$ fortiden, aner vi ikke, hvad der sker i lobet af den og lever spandt med i begivenhederne.

For det andet kan man fortalle det fortidige 1 sin fortidighed dvs. nu er det ikke blot begivenhederne, der foregar i fortid, men de fortalles som foregasende, som afsluttede. Vi ved allerede det hele. Ikke blot begivenhederne, men ogsa vores viden hensattes altsa til fortiden. Denne modus benytter man f.eks. typisk, når man skal skrive sine erindringer, og det er helt parallelt, nar Reitz kalder sin serie for en "Chronik".

Egentig ex det lidt vanskeligt at definere hvor denne modusforskel horer hjemne i tekster. I litteraturen er det ikke blot et spфrgsmal om verbernes tider, eftersom man jo udmarket kan aktualisere fortiden ved hjolp af datidsformer. Endnu mere spendende er sporgsmalet nar det galder filmbilieder, eftersom disse jo angiveligt ikke engang har disse ressourcer. 
Reitz novner selv 1 forordet til sit udgivne manuskript, at et planlagt afsnit blev udeladt pa grund af denne vanskelighed. 3$)$ Afsnittet skulle skildre hvordan - ved krigens afslutning - at personernes fortid og fremtid pa sarlig made knyttedes sammen med begivenhederne $i$ en drommeagtig form, som erindringer. Men afsnittet blev udeladt, fordi filmbilleder altid ex 1 fortallerisk nutid, siger Reitz.

Ikke desto mener jeg, at Reitz har fundet en billedtype og anvendt den 1 serien, som svarer godt til den bestrabelse, hans bemærkning iфvrigt videner om. I forhold til manuskriptet har han $i$ serien helt opgivet den konstante vekslen mellem historisk nutid og flash-backs. Det kan vare fordi flash-backs i sig selv ikke evnex at visualisere fortiden $i$ sin fortidighed. Flashbacks er aktualiserende billeder, hvis fortidighed blot beror pa., hvordan de dateres af den egentlige handing. I det hele taget er flash-backs sjældent gode, fordi de er sa vanskelige at legitimere 1 fortallingens univers.

Reitz har altsa varet tvunget til - i virkeligheden aner jeg selvfølgelig ikke, hvad Reitz har tankt - at udvikle billeder som kume skildre den himmel, hvor de taler "Hunsrücker-platt". En usynilg hukommelsesrealitet, som skulle synliggores. Altsa noget, der bryder igennem i en verden, der allexede er sat kors over. Som korsene ikke kan holde tilbage, ligesom korset ikke kan holde Dracula pa afstand. Han har altså måttet finde nogle billeder, hvor fortidigheden fungerer som en synlig hinde, hvor himlen bryder igennem. Men himlen er blot smerten i hukomnelsen, et sar uden krop.

Fortiden findes jo ikke $i$ sin fortidige eksistens. Stederne, husene, trappen og kokkenet findes kun her og nu. Fysisk kan de ikke eksistere $i$ fortiden. De er blot spor, men spor er ikke selv fortid. Genstande er kun spor, fordi nogen har "efterladt" dem. Og sporene betyder dem, der hax efterladt dem uden at vise dem. Spor er tegn, der betyder uden at vise, uden at lade komme til syne. Det hemmelighedsfulde ved spor er netop den usynlige dybde, de kan skabe til dem, der efterlod dem. De synlige billeder $i$ "Heimat" synes at have en sadan sporenes hemmelighed. 


\section{Billederne som tidskrystal}

Et tidskrystal billede er netop en umarkelig dobbelthed af det dode foto og den levende bevagelse 1 det. Det er tid, der passerer i den brokdel af et $\phi j e b l i k$, hvor fotoet $\mathbf{a}$. $1 \mathrm{iv}$, og hvor det stivner igen. Denne funktion har Reitz skaret ua i pap, eftersom hvert afsnit begynder og slutter med aisse overgange fra foto til liv og tilbage igen.

Krystalfunktionen skal forstaes som en sadan umarkelig dobbelthed, hvor det ikke som sadan er fortiden, der visualiseres, men derimod selve tidens substanslose passage. Altsa en bevagelse i tidsaksen presser sig ind $i$ billederne.

Den eksplicitte fortaller 1 "Heimat" er jo en, der kigger på fotos fra dengang. Han ved, hvad der skete sidenhen og lagger ikke skjul pa, at det, der kom efter, ikke var noget at rabe hurra for. Tiden kunne godt vare standset pa de og de tidspunkter, siger han. Denne fortallerfunktion bliver endnu mere interessant, năr man tankex pä, at den gentages i det fortalte. Her er der f.eks. ogsa en, Eduard, som fotograferer og et par gange udtaler, at nu ville han gerne have tiden til at sta stille. Men ogsa de andre personer fikserer de begivenheder de er $i$. De registrerer deres livsфjeblik som allerede et stykke fortid. Netop denne fornemelse er mest udpraget nar man forlader noget, f.eks. găr hjemmefra, sa er det ofte som om netop det, man forlader, sa ogsă indtager sin plads i fortiden. Og i "Heimat" tager de afsked hele tiden.

Men lad os se, hvor raffineret Reitz ongases denne type billeder af det pa engang aøde og levende. F.eks. afsnittet "Weihnacht wie noch nie".

Det er juleaften 1934. Vi er i kirken. Kirkekoret dirigeres af en lille skrumpet mand med stive og nasten marionetagtige bevegelser. Koret selv filmes fra siden med et blødt gyldent lys faldende på en sadan måde, at sangernes silhuetter udviskes gradvist ned gennem rakken. Dexefter filmes koret forfra og forekommer nu traagtige, dфdningeagtige, som var de udskarne figurer pă orglet. 
Herefter filmes Lucie, Eduard og Wilfxied. I lyabilledet hores først Lucie synge alene med skinger og ubehagelig stemme, derefter falder Wilfried ind, så Eduard og siden hele menigheden. Man undrer sig over, hvad denne perspektivering 1 lydbilledet skal tjene til. Fortolkningsmassigt kan det have noget at gore med at der ogsa er en anden tro 1 deres $\phi j n e$, som wilfried siger bagefter. Men jeg fornemmer ogsa, at Reitz filmer en erindring om Lucie og Wilfied. Erindringen on en fornemmelse af, at der var noget mellem dem. Eduard sidder 1 hvert fald og skxver, som om han ogsa fornemmede noget.

Sa folger en sekvens, hvor nazisten Wiegand ses ind gennem et oplyst vindue (med kors) idet han lagger en nazistisk juleplade pa grammofonen. Igen perspektiveres lydbilledet, eftersom kameraet. begynder at vandre rundt til andre vinduer 1 landsbygen, mens vi stadig hører pladen. I tusmorket kommer en kxlk med en dreng glidende forbi på sneen - som om han gled lige ud af et gammelt julekort, ville jeg sige.

Sa kommer simon-familien ud af kirken og stiller op til den sadvanlige fotografering. Her bemærker man, hvordan Eduard tøver, som om der var noget, han ville trenke, inden han siger "freundlich". Under den efterfølgende julemidag far Eduard hoste og ma gå udenfor et $\phi j e b l i k$. Moderen folger efter og Eduard bemærker til hende, hvor dejligt, det ex hjemme. Den stjernehimmel, han kigger op pa, er tydeligvis en kulisse. Să vender Eduard sig nasten voldsomt om i nerbillede, som om der var nogen, der havde kaldt på ham.

Reitz benytter ofte disse teknikker rundt om $i$ serien. Her er det indlysende, at han ikke vil fortalle os, at sa er det jul igen. Det er derimod arkzologien 1 billederne, der er vigtig. Al den virtualitet, der gemmer sig $i$ beretningens afsluttethed. For at fa "Hunstucker-himlen" frem 1 billederne, gor han den synlige himmel til kliche.

Argumentationen for disse krystalbilleder hjalpes pa vej af de mange eksplicitte krystaltemaer i serien. Forst og fremest selvfolgelig det, at schabbach i sig selv er det velegnede sted for en optisk fabrik ned klar luft og dybe grotter. 


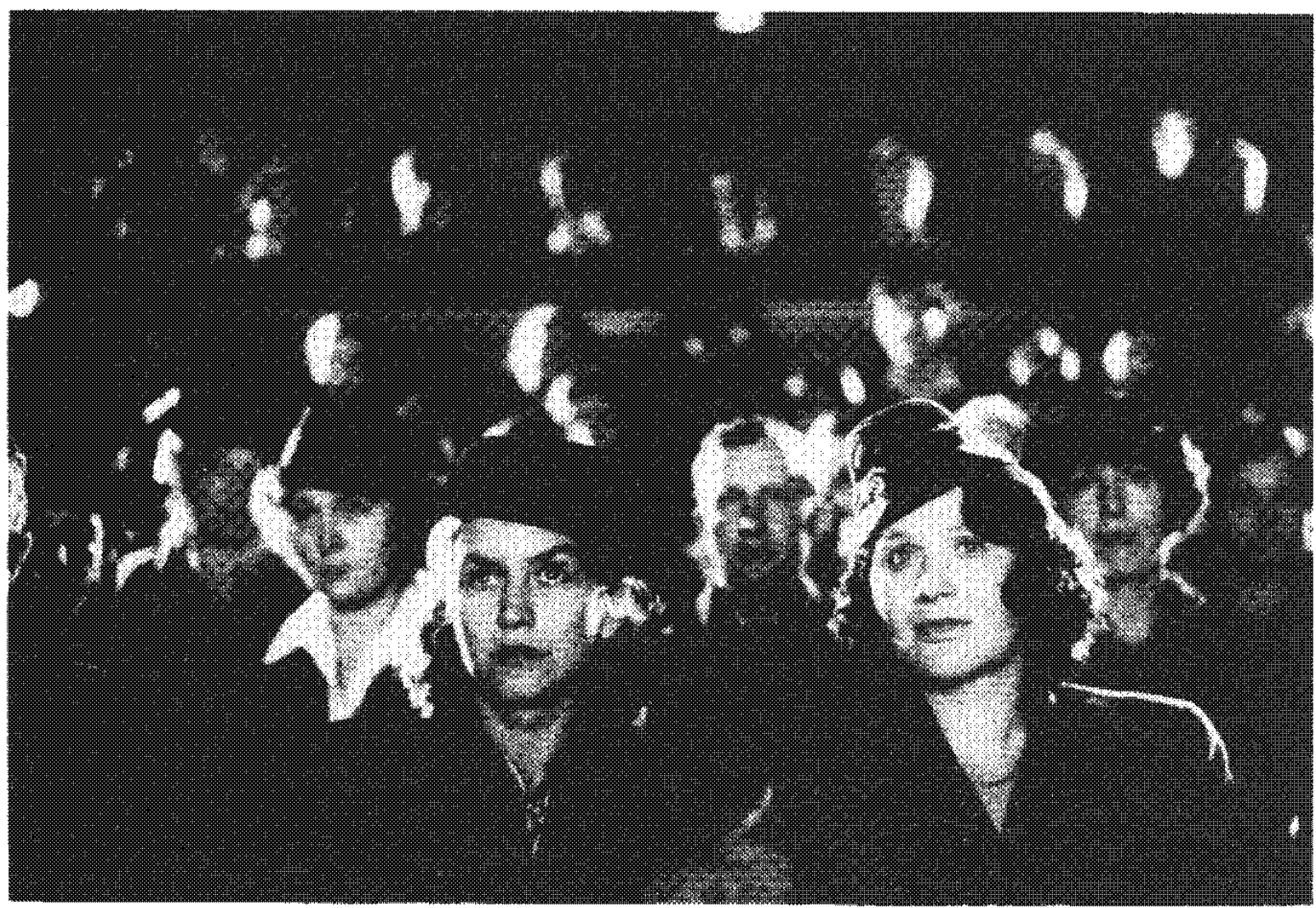

Maria og Paulne sex en Zarak Leander-film. Dex ex mange billeder i serien af personer som ser. I baggrunden udviskes de seende ansigter gradvist.

Men vigtigere er krystaltemaet til slut i serien. Under de levendes og de dødes fest stax Anton, det optiske geni, og fumler med en mangefacetteret linse. I lobet af denne fest, hvor vi ogsa no-

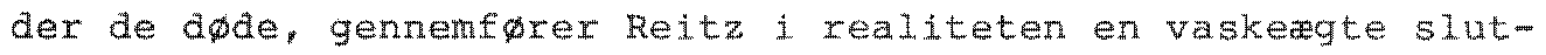
ning om synlighed og usynlighed. Sporgsmbl valter frem pa skarmen: Horfor kommer Glasisch fra "Dunkelheit" til "Klarheit" da han dor. Horfor kan de dode ikke se Mathias Simon, nar han er blind? Hvad ex det Anton ser pa skiltet, da han dør? osv.

\section{Krystallets kredsløb}

Krystalbilleder kan skelnes indbyrdes alt efter, hvoraan det snavre kredslob mellem nutid og fortid, synilghed og usynighed, konkretion og virtualitet realiseres i dem. Dette snavre kredsI $\phi \mathrm{b}$ kan samtidig betragtes som grundelement i seriens storform. Altsa på den madde, at krystallets minimalspejling er en model 
for, hvordan hukommelsesarbejdet generelt fungerex 1 serien. Den er jo tydeligvis anlagt på den made, at en begivenhed som navnt skildres $i$ en fortidig modus, hvorefter den samme begivenhed dukker op senere $i$ form af virtuel hukommelse. Altsa at noget anlagges som fremtiaig hukommelse, for derefter senere faktisk at blive vakket. Eksempelvis den made simonfamiliens hus langsomt tømmes for mennesker og liv, og hvor personer igen og igen kommer tilbage i huset og vakker erindringen on det, der var.

Hukommelseslogikken 1 denne konstruktion ex vanskelig at udrede. Der er bade noget perfekt og lukket over dette kredsl $\phi b$, men samtidig ogsa noget lunefuldt jve. linsens tilsyneladende tilfaldige reflektion af farver eller $\mathrm{s} / \mathrm{h}$.

Glemslen spiller ogsa en rolle. Nogen af personeme glemmes helt (Rlärchen, Apolionia) dvs, det gфr de ikke. De bliver blot aldrig synligt antydet mere, for dex ex ingen spor af dem. Robert, som dør 1 Rusland forbliver halvskjult. Blandt de dode ligger der en mork skygge over hans ansigt, og pa gravstenen er hans navn forsvundet 1 blomsterne. Egentilg ex det denne vekslende grad af virtualitet $i$ billederne, som spinder den trad, vi instinktivt kan følge, men vanskeligt forklare.

NOTER

1. E. Reitz: "Synligt. Usynligt". 1 Chaplin nr. 202, 1986.

2. M. Mexleau-Ponty: Le visible et I'invisible, paris 1964.

(Citatet her i P. A. Brandts oversattelse i Tegn.)

3. E. Reitz \& P. Stelnbach: Helmat. Eine deutsche Chronik. Nördlingen 1985.

Niels-Aage Nielsen er konsulent i Danmarks Radios medieforskningsafdeling. 


\title{
Programfladens æstetik
}

\author{
EN ANALYSE AF KANAL 2 OG WEEKEND TV
}

\section{Af Stig Hjarvard og Henrik Søndergaard}

\begin{abstract}
Programmex fordeler sig i genrer, som har mange fallestrak. Fitm Ligner fitm, nyhedsudsendelser nyhedsudsendezser, rundbordssamtater rundbordssamtaler, o.s.v. pä det overordnede plan. Narr tv-stationer forsqger at markere sig iforhold tit hinanden, er dette derfor ikke sartig tydeligtpă enkelt-programniveauet, forst nar programfladen tages op tit analysebliver profizen markant. Det er pa denne baggrund at Stig HjarvardogHenrik Sondergaard i artikelen analyserex cotetikken $i$ Kanal 2 's og Weekend TV's programflader. Programfladeanalysen er ny i den danske Medieforskning.
\end{abstract}

Rort før someren 1985, da Weekend TV (WTV) havde sendt i knapt et halvt år, holdt stationens bestyrelse møde.

Bestyrelsens budskab til stationslederen Hans Morten Rubin var meget klart: WrV skulle gennem en kraftig foryngelseskur; det kunne simpelthen lkke $g a$, at WTV "lignede en dålig udgave af Danmarks Radio".

Og Hans Morten Rubin gjorde faktisk noget ved det. Han nøjedes ikke med smajusteringer af enkelte programmer, men efter sommerferien prasenterede han en markant anden sendeflade, der fik seertallene til at stige. Det var ogsa nddvendigt, hvis WTV skulle gøxe sig hâb om at opfylde sin mission som politisk murbrakker for såvel reklamefinansiering som et TV-2. Som politisk pressionsinstrument skulle stationen gore sig synligi den offentige debat, og det kravede bade et image af noget nyt og anderledes TV og høje seertal.

Seertal er faktisk gået hen og blevet en betydelig faktor i tvkonkurrencen i Danmark, hvilket bl.a. betyder, at seerundersфgelser nu ikke ex offentligt tilgangelige, men forretningshemeligheder. Berlingske Tidende har endog kunnet referere, at Jens Jordan og Hans Morten Rubin fra WTV pa et tidspunkt havde indkaldt airektøren for analyseinstituttet AIM og kravet, at AIM gjorde 